\title{
Right ventricular endocardial potential in - acute massive pulmonary embolism
}

\author{
K. Chatterjee, G. C. Sutton, and G. A. H. Miller \\ From the Cardiac Department, Brompton Hospital, London
}

We have observed a constant and significant reduction in the amplitude of the endocardial potential recorded from the right ventricle in a group of 8 patients with acute massive pulmonary embolism at the time of the initial diagnostic cardiac catheterization and pulmonary arterio- graphic study. Despite the variable haemodynamic and arteriographic resolution of embolism obtained with treatment, all but one patient exhibited a return of the amplitude of the endocardial potential recorded from the right ventricle to normal at the time of a second study 56 hours to I9 days later. The significance of such changes in endocardial potential is unknown, but it is suggested that reduction in endocardial potential may reflect acute myocardial stress.

\begin{abstract}
A fall in the amplitude of the right ventricular endocardial potential has been reported in patients with acute myocardial infarction (Chatterjee, Sutton, and Davies, 1968; Parker, Furman, and Escher, 1968; Chatterjee et al., 1970) and appeared to show some relation to the degree of shock and of clinical heart failure (Chatterjee et al., 1970). Such a fall in

" endocardial potential might reflect impaired myocardial function rather than being a specific consequence of myocardial infarction. Acute massive pulmonary embolism is a situation in which there may be impaired myocardial function but there is no localized myocardial infarction. In order, therefore, to investigate further the possibility that a low right ventricular endocardial potential may

v reflect impaired myocardial function, we have made serial measurements of the amplitude of the right ventricular potential in 9 patients before and after treatment of massive pulmonary embolism.
\end{abstract}

\section{Subjects and methods}

- Nine patients (8 women, I man, aged 31 to 69 years) were investigated within 48 hours of the occurrence of massive pulmonary embolism. In all patients pulmonary arteriography confirmed massive pulmonary embolism involving at least half of the major pulmonary artery branches. In all but one patient pulmonary embolism had occurred during convalescence from a surgical

-procedure; none had any pre-existing cardiorespiratory disease. Cardiac catheterization was performed using conventional techniques, pressure measurements being referred to the mid-

Received 24 May 197 I. chest level. An electrode catheter ${ }^{1}$ permitted the recording of intracardiac pressures as well as the right ventricular endocardial potential. The unipolar endocardial potential was obtained by connecting the ' $V$ ' chest lead with the distal electrode of the bipolar electrode catheter (and recorded at a paper speed of $25 \mathrm{~mm} / \mathrm{sec}$ ). The amplitude of the potential was measured as the total deflection of the QRS in $\mathrm{mV}$, and the measurement averaged from ro complexes showing an ST elevation contact pattern (Levine et al., 1949). Right ventricular endocardial potentials were recorded from the apical region of the right ventricle and care was taken to record from the same site at the second study. Values for potentials so obtained were compared with previously reported normal values recorded in similar fashion (Chatterjee et al., 1970).

After a period of treatment with heparin or streptokinase (7 patients) or pulmonary embolectomy (2 patients), the study was repeated at an interval of 56 hours to 19 days in 8 of the 9 patients. The severity of embolism at the initial study and the response to treatment was assessed from the pulmonary arteriogram by an independent observer.

\section{Results (Table)}

At the time of the first study the mean value for right ventricular endocardial potential was $3.3 \pm \mathrm{I} \cdot 5 \mathrm{mV}$ (range $\mathrm{I} \cdot \mathrm{I}-5.4 \mathrm{mV}$ ) and this value was significantly $(P<0 \cdot 00 \mathrm{I})$ lower than the previously reported normal value of $9.5 \pm 2.8 \mathrm{mV}$ (range 6-13 mV) (Chatterjee et al., 1970). Lower values for right ventricular endocardial potentials were observed in

1 Zucker multi-purpose electrode catheter. United States Catheter and Instrument Corporation. 
T A BLE Haemodynamic findings and right ventricular endocardial potentials before and after treatment in patients with massive pulmonary embolism

\begin{tabular}{|c|c|c|c|c|c|c|c|c|}
\hline \multirow[t]{2}{*}{$\begin{array}{l}\text { Case } \\
\text { No. }\end{array}$} & \multirow[t]{2}{*}{$\begin{array}{l}\text { Duration } \\
\text { (hr) }\end{array}$} & \multirow{2}{*}{$\begin{array}{l}R V \\
\text { end-diast. } \\
\text { pressure } \\
(m m H g)\end{array}$} & \multicolumn{2}{|c|}{$\begin{array}{l}\text { Pulm. art. } \\
\text { pressure }\end{array}$} & \multirow[t]{2}{*}{$\begin{array}{l}\text { Art. } \mathrm{O}_{2} \\
\operatorname{satn}(\%)\end{array}$} & \multirow[t]{2}{*}{$\begin{array}{l}A V \mathrm{O}_{2} \text { diff. } \\
(\mathrm{ml} / \mathrm{IOO} \mathrm{ml})\end{array}$} & \multirow{2}{*}{$\begin{array}{l}R V \\
\text { endocard. } \\
\text { potential } \\
(m V)\end{array}$} & \multirow[t]{2}{*}{$\begin{array}{l}\text { Pulmonary arterio- } \\
\text { graphic assessment }\end{array}$} \\
\hline & & & Syst. & Mean & & & & \\
\hline \multirow[t]{2}{*}{$\mathbf{I}$} & IO & 15 & 35 & 20 & 89 & $6 \cdot 5$ & $\mathbf{I} \cdot \mathbf{I}$ & \\
\hline & 82 & I0 & 23 & 16 & 94 & $3 \cdot 7$ & $\mathrm{I} \cdot 6$ & Moderate improvement \\
\hline \multirow[t]{2}{*}{2} & 3 & 13 & 42 & 22 & 87 & $7 \cdot 8$ & $1 \cdot 7$ & \\
\hline & 75 & 6 & 35 & 19 & 90 & $5 \cdot 6$ & $6 \cdot 6$ & No improvement \\
\hline \multirow[t]{2}{*}{3} & 6 & 12 & 40 & 29 & 9I & 10.4 & $2 \cdot I$ & \\
\hline & $19 \mathrm{dy}$ & 4 & 25 & 14 & - & - & $6 \cdot 9$ & Obvious improvement \\
\hline \multirow[t]{2}{*}{4} & 5 & I2 & 36 & 26 & 80 & $7 \cdot 3$ & $2 \cdot 8$ & \\
\hline & 56 & II & 35 & 25 & 94 & $6 \cdot 3$ & 5.0 & Obvious improvement \\
\hline \multirow[t]{2}{*}{5} & 5 & 12 & 33 & 22 & 62 & $9 \cdot I$ & $3 \cdot 3$ & \\
\hline & 125 & 5 & 30 & 18 & 97 & $7 \cdot 1$ & $9 \cdot 3$ & No improvement \\
\hline \multirow[t]{2}{*}{6} & 48 & 6 & 47 & 27 & $9 I$ & $8 \cdot 3$ & $5 \cdot 0$ & \\
\hline & 120 & 5 & 40 & 23 & 91 & $8 \cdot 2$ & $10 \cdot 0$ & Slight improvement \\
\hline \multirow[t]{2}{*}{7} & 12 & 14 & 62 & 34 & 86 & $8 \cdot 9$ & $5 \cdot 4$ & \\
\hline & 84 & 6 & 24 & 13 & 94 & $7 \cdot 7$ & $9 \cdot 2$ & Moderate improvement \\
\hline \multirow[t]{2}{*}{8} & 36 & I5 & 40 & 26 & 91 & $7 \cdot 0$ & $4 \cdot 2$ & \\
\hline & 108 & 9 & 40 & 25 & 99 & $5 \cdot 1$ & $9 \cdot 3$ & Slight improvement \\
\hline \multirow[t]{2}{*}{9} & 48 & 9 & 47 & 24 & 84 & 5.5 & $4 \cdot 3$ & \\
\hline & 120 & 5 & 25 & 15 & 88 & $4 \cdot 3$ & - & Moderate improvement \\
\hline
\end{tabular}

$\star$ Duration $=$ Approximate duration of embolism at time of study.

patients studied earlier after the occurrence of massive pulmonary embolism.

The endocardial potentials were measured in 8 of the 9 patients after a period of treatment and at a time ranging from 56 hours to I9 days after the first study. The post-treatment values for right ventricular endocardial potentials (mean $7 \cdot 2 \pm 2 \cdot 8 \mathrm{mV}$, range $1 \cdot 6-10 \cdot 0$ $\mathrm{mV}$ ) were higher in all patients than at the time of the first study, and these increases were significant $(P<0.005)$. In 6 of the 8 patients in whom this measurement was repeated the value was now in the normal range. One patient had had a pulmonary embolectomy after unsuccessful treatment with heparin and, in this patient, restudied within 24 hours of operation, the value was just below the normal range. Only in I patient was there no significant increase at the time of restudy.

In parallel with the increase in amplitude of right ventricular endocardial potential at the second study there was usually a reduction in right ventricular end-diastolic pressure and in arteriovenous oxygen difference; arterial oxygen desaturation, previously present in all patients, was absent or less obvious in most patients at the time of restudy. In contrast, 4 of the patients (Cases 2, 5, 6, and 8) showed little arteriographic improvement and only 4 (Cases I, 3, 4, and 8) had a normal pulmonary artery systolic pressure at the time of the second study despite increase in the amplitude of the endocardial potential.

\section{Discussion}

Since reduction in the amplitude of the right ventricular endocardial potential has now been observed in two apparently dissimilar conditions, massive pulmonary embolism and myocardial infarction, it is apparent that neither condition per se is responsible for the reduced potential. Instead some factor common to the two conditions must be responsible for the observed findings.

Endocardial potentials, whether recorded from the right or the left ventricle, represent total depolarization activity of both ventricles though the proximity effects contribute significantly as the endocardial electrodes are 'direct leads' (Sodi Pallares and Testelli, 1965). Therefore, changes in the endocardial potential, irrespective of the site of recording, 
might be expected to be produced by changes in the electrical forces of depolarization, either of the right or of the left, or of both ventricles. In patients with acute myocardial infarction, the left ventricle is involved and the right is usually spared. In these patients, therefore, it is likely that the acute stress imposed on the left ventricle after infarction produces changes in left ventricular depolarization electrical forces which are reflected in right ventricular endocardial potentials. Experimental work (Chatterjee and Rouse, 197I) suggests that the fall in endocardial potential after acute myocardial infarction is not simply due to the loss of local electrical forces nor due to the phenomenon of cancellation between electrical forces generated at different parts of the heart. That localized infarction per se is not the cause of fall in endocardial potential, is further supported by the present observation of low endocardial potential in patients with acute massive pulmonary embolism, who suffer from sudden severe circulatory stress which is not precipitated by

- localized myocardial infarction. It seems, therefore, that sudden circulatory stress, whether due to acute massive pulmonary embolism or to acute myocardial infarction, is likely to be the precipitating factor for the fall in endocardial potential though the precise mechanism remains unknown. In speculating

2 as to what this mechanism may be we may also postulate that it is related to improvement in the clinical state of the patient with time. Thus both in myocardial infarction and in pulmonary embolism the amplitude of the right ventricular endocardial potential returned to normal in those patients whose clinical state improved. Moreover, in pulmonary embolism the highest values for right ventricular endocardial potential were observed in patients seen later after the occurrence of embolism, suggesting that some spontaneous recovery is occurring which is independent of treatment. In 2 other untreated patients (not included in the present series) studied approximately 7 days after the acute event, the level was in the normal range despite severe haemodynamic disturbance and angiographic demonstration of massive embolism. Thus recovery of the endocardial potential may be related primarily to time rather than to haemodynamic alterations.

In the case of pulmonary embolism the clinical improvement that was observed was accompanied by a reduction in end-diastolic pressure as well as an increase in arterial oxygen saturation and a narrowing of AV difference, reflecting an increase in cardiac output. It was not always accompanied by a reduction in right ventricular systolic pressure. This recalls the observation that right ventricular endocardial potential may actually be increased in cases of chronic right ventricular stress (Chatterjee et al., 1970). Thus a reduced potential has now been observed in 2 dissimilar conditions characterized by acute myocardial stress; while the mechanism remains obscure, the observation is of interest and suggests that measurement of endocardial potential may differentiate conditions of acute from chronic myocardial stress.

\section{References}

Chatterjee, K., Davies, G., Harris, A., and Leatham, A. (I970). Fall of endocardial potentials after acute myocardial infarction. Lancet, $\mathbf{r}, 1308$.

Chatterjee, K., and Rouse, W. (I97I). Ventricular endocardial potentials after experimental coronary artery occlusion in dogs. American Heart fournal, 82, 352.

Chatterjee, K., Sutton, R., and Davies, J. G. (I968). Low intracardiac potentials in myocardial infarction as a cause of failure of inhibition of demand pacemakers. Lancet, I, 5 I I.

Levine, H. D., Hellems, H. K., Dexter, L., and Tucker, A. S. (1949). Studies in intracardiac electrocardiography in man. II. The potential variations in the right ventricle. American Heart fournal, 37, 64.

Parker, B., Furman, S., and Escher, D. W. J. (I968). Input signals to pacemakers in a hospital environment. Annals of the New York Academy of Sciences, $167,823$.

Sodi-Pallares, D., and Testelli, M. R. (1965). Endocardial and epicardial electrocardiograms. In Examination of the Cardiac Patient, 3rd ed., pp. 4379. Ed. by A. A. Luisada. McGraw-Hill, New York.

Requests for reprints to Dr. Graham Miller, Brompton Hospital, London S.W.3. 